Research Journal of Applied Sciences 14 (1): 45-48, 2019

ISSN: $1815-932 \mathrm{X}$

(C) Medwell Journals, 2019

\title{
Determination the Effect of Gamma Radiation on (CR-39, CN-85) Detectors by Using of Penetration of (He-Ne) Laser Beam
}

\author{
${ }^{1}$ Hussain A. Al-Jobouri, ${ }^{2}$ Fala H. Taha, ${ }^{3}$ Laith Ahmed Najam and ${ }^{1}$ Wijdan Thamer Faaz \\ ${ }^{1}$ Department of Physics, College of Science, Al-Nahrain University, Baghdad, Iraq \\ ${ }^{2}$ Madanet Alelem University College, Baghdad, Iraq \\ ${ }^{3}$ Department of Physics, College of Science, Mosul University, Mosul, Iraq
}

\begin{abstract}
The penetration of (He-Ne) laser beam on the Nuclear Track Detectors (NTDs) types CR-39 and CN-85 was measured after the gamma radiation effects with doses $(0,42.3,84.6,126.9,169.2,211.5,253.8$ Gy) and $(0,12.7,25.4,38.1,50.8,63.4,76.1,88.8 \mathrm{~Gy})$ or CR-39 and CN-85 detectors, respectively. The penetration of $(\mathrm{He}-\mathrm{Ne})$ laser beam was also measured after the stress effect at the range $(50,55,65,100,102,106 \mathrm{~N})$ for both detectors. The penetration coefficient of $(\mathrm{He}-\mathrm{Ne})$ laser beam $\ln \left(\mathrm{P}_{0} / \mathrm{P}_{\text {av }}\right)$ was calculated when $\mathrm{P}_{0}$ is the penetration of laser beam through detectors without gamma radiation and stress effects and $\mathrm{P}_{\mathrm{av}}$ is average the penetration of laser beam through detectors with the gamma radiation and stress effects. The value of $\ln \left(\mathrm{P}_{0} / \mathrm{P}_{\text {av }}\right)$ was increase with increase of gamma radiation dos until to 220 and 75 Gy for CR-39 and CN-85 detectors, respectively. While the value of $\ln \left(\mathrm{P}_{0} / \mathrm{P}_{\mathrm{av}}\right)$ was increase with increase of stress effect until to $1.6 \times 10^{6} \mathrm{~N} / \mathrm{m}^{2}$ and $12 \times 10^{6} \mathrm{~N} / \mathrm{m}^{2}$ for CR-39 and CN-85 detectors, respectively. This study shows there is a possibility to use the penetration of $(\mathrm{He}-\mathrm{Ne})$ laser beam to measure the effect of gamma radiation and stress on anther (NTDs).
\end{abstract}

Key words: Nuclear track detectors, CR-39, CN-85, gamma radiation, (He-Ne) laser beam, stress, strain effect

\section{INTRODUCTION}

Nuclear Track Detectors (NTDs) used to measurements the effect of particulate radiation, including alpha particles (Mohammad and Azawe, 2013) and thermal neutrons (Kumar et al., 2009, 2010) protons (Sinenian et al., 2011) in addition to the ionic particles (Kumar et al., 1982).

It has been used to measure the radiation pollution of alpha rays in the environmental fields through routine radiological survey or in cases of radiation accidents accompanied by alpha emitters (Al-Saad and Abbas, 2001).

NTDs used also, to measurement of non-particulate radiation, including gamma radiation (Malek and Chong, 2002) UV radiation (Wong and Hoberg, 1982; Chun, 2007) laser (Zaki et al., 2013) and microwave radiation (Al-Jobouri et al., 2012). It was proved through these studies that the radiation effect of non-particulate radiation changed in the physical specifications of the NTDs. These change include optical absorbance through UV-visible spectroscopy (Al-Jobouri et al., 2015), relative transmittance of infrared radiation through -FTIR spectroscopy (Raouf, 2013). Moreover, NTDs types CR-39 and Lexan detectors were calibrated as low-LET radiation dosimeters (Sinha et al., 1998; Tavera et al., 2005). The effect of non-ionizing radiation (IR, UV and laser) on NTDs was studied by Prasher et al. (2009) for determining the effect of IR irradiation on some polymers and studies the modifications owing to irradiation by analyzing the X-Ray Diffraction (XRD) and UV-visible spectra (Rafique et al., 2010).

The mechanical specification as stress and strain of CR-39 studies by Ali (2006) which showing the change in the value of stress produce the inversing in strain value. Mandal and Nagahanumaiah (2014) found that the relationship between the height/depth of the CR-39 detector was increased by increasing the stress.

Laser beam was used with NTDs in many studies (Zaki et al., 2013) by measuring the radiation effect of the laser beam. Where the effect of gamma radiation on NTDs was measuring by UV-visible, FTIR spectroscopy, thermal diffusion analyzing (Al-Jobouri et al., 2018; Neamah, 2017) calculated the radiation effect of gamma rays by measuring the permeability of the laser beam. In this study the effect of gamma radiation and stress on CR-39 and CN-85 detectors was measuring by using the penetration of $(\mathrm{He}-\mathrm{Ne})$ laser beam

\section{MATERIALS AND METHODS}

Two types of nuclear track detectors NTDs were used in this study. The first one was CR-39 detector with thickness $1200 \mu \mathrm{m}(10 \times 5 \mathrm{~cm})$ and density $1.32 \mathrm{~g} / \mathrm{cm}^{3}$, supplied by TASTRAK type (Track Analysis System Ltd.), UK and having a chemical formula $\mathrm{C}_{12} \mathrm{H}_{18} \mathrm{O}_{7}$.

Corresponding Author: Hussain A. Al-Jobouri, Department of Physics, College of Science, Al-Nahrain University, Baghdad, Iraq 


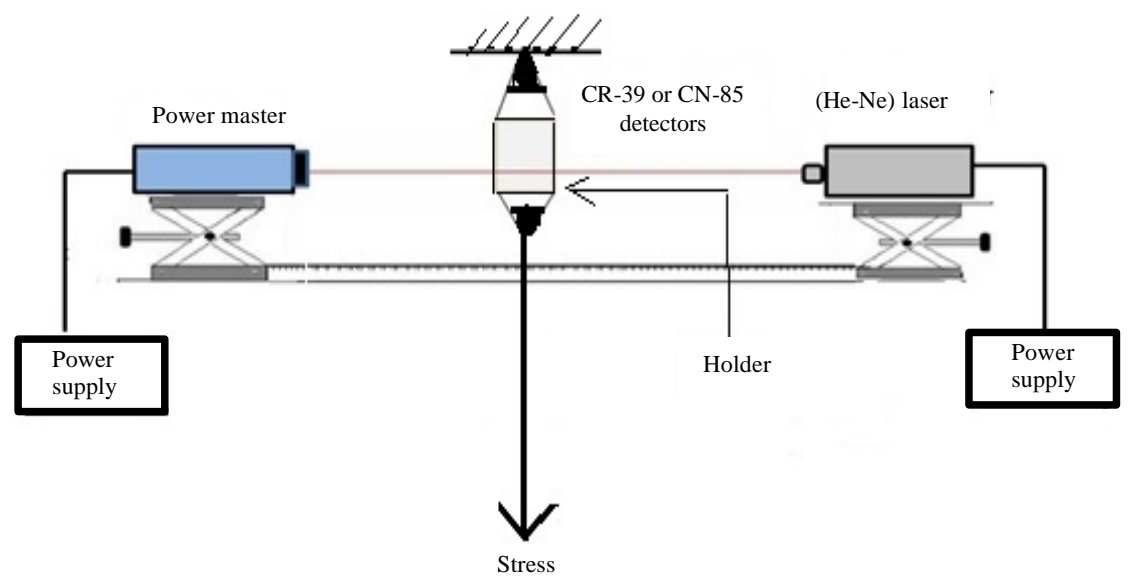

Fig. 1: Schematic of (He-Ne) laser beam penetration with following apparatus, power meter, (He-Ne) laser beam, CR-39 or CN-85 detectors, jack (holder), power supply

The second type of NTDs was the CN-85 detectors with thickness $200 \mu \mathrm{m}$ density $1.42 \mathrm{~g} / \mathrm{cm}^{3}$, manufactured by the Eastman Kodak Company, Rochester, New York and having a chemical formula $\mathrm{C}_{6} \mathrm{H}_{8} \mathrm{O}_{9} \mathrm{~N}_{2}$.

Gamma radiation effect: $\mathrm{CR}-39$ and $\mathrm{CN}-85$ gamma irradiation detectors exposed to gamma radiation from cobalt-60 source with dose rate $0.45 \mathrm{~Gy} / \mathrm{min}$. The distance between the gamma source and NDTs detectors was 15 $\mathrm{cm}$. The range of gamma radiation dose were $(0,42.3,84.6$, $126.9,169.2,211.5,253.8 \mathrm{~Gy})$ and $(0,12.7,25.4,38.1,50.8$, $63.4,76.1,88.8$ Gy) for $\mathrm{CR}-39$ and $\mathrm{CN}-85$ detectors, respectively.

Mechanical stress effect: $\mathrm{CR}-39$ and $\mathrm{CN}-85$ detectors exposed by mechanical stress with range values $(50,55$, $65,100,102,106 \mathrm{~N})$.

Figure 1 shown the arrangement setup of $(\mathrm{He}-\mathrm{Ne})$ laser beam with apparatus included $(\mathrm{He}-\mathrm{Ne})$ Laser beam source, power meter, CR-39 or CN-85 detectors, power supply, jack (holder).

The (He-Ne) laser penetration technique used to measuring the average of penetration rate $\mathrm{P}_{a v}$ at gamma radiation or stress effect comparing with laser Penetration- $\mathrm{P}_{0}$ without above effect. The power of penetration ( $\mathrm{He}-\mathrm{Ne}$ ) laser beam was $15 \mathrm{~mW}$ and wavelength $632 \mathrm{~nm}$. The specification of laser power meter was model (RF-1501 Shimadzu, Ltd.,) this power meter used to measuring the penetration rate- $\mathrm{P}$ at a distance of $13 \mathrm{~cm}$ from the detector.

\section{RESULTS AND DISCUSSION}

Gamma irradiation: Figure 2 shown the effect of gamma radiation on CR-39 detector with laser penetration factor $\ln \left(\mathrm{P}_{0} / \mathrm{P}_{\mathrm{av}}\right)$ which shown the increase in $\ln \left(\mathrm{P}_{0} / \mathrm{P}_{\mathrm{av}}\right)$ with

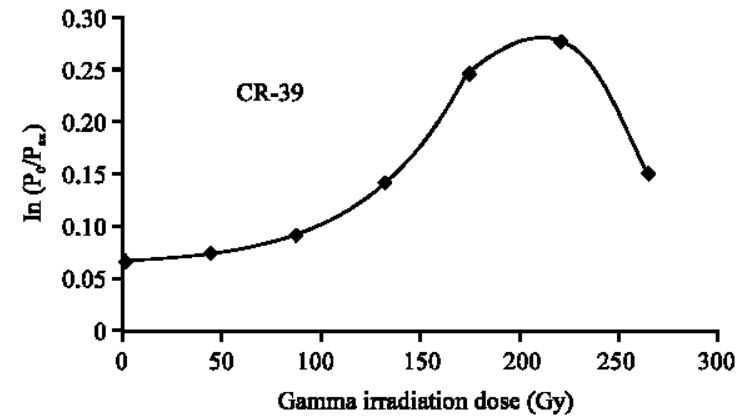

Fig. 2: The relationship between the effect of gamma irradiation on CR-39 detector with (He-Ne) laser penetration factor $\ln \left(\mathrm{P}_{0} / \mathrm{P}_{\text {av }}\right)$

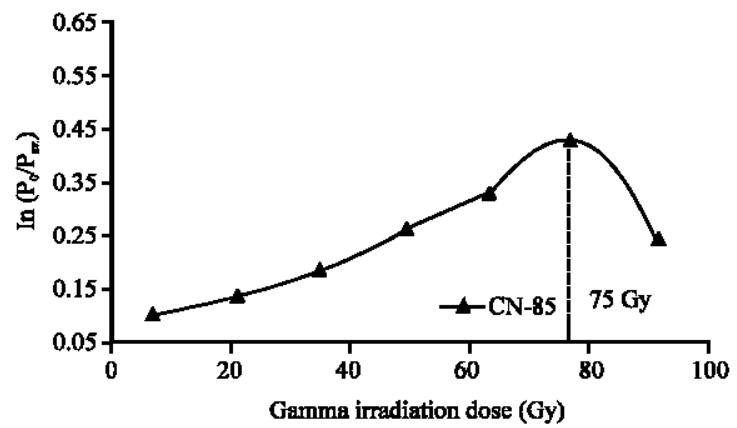

Fig. 3: The relationship between the effect of gamma irradiation on $\mathrm{CN}-85$ detector with $(\mathrm{He}-\mathrm{Ne})$ laser penetration factor $\ln \left(\mathrm{P}_{0} / \mathrm{P}_{\text {av }}\right)$

increase in gamma irradiation until to 220 Gy which represent of maximum response and dropping after this dose.

Figure 3 shown the effect of gamma radiation on $\mathrm{CN}-85$ detector on laser penetration factor $\ln \left(\mathrm{P}_{0} / \mathrm{P}_{\mathrm{ar}}\right)$ which appear the increase in $\ln \left(\mathrm{P}_{0} / \mathrm{P}_{\text {ay }}\right)$ with increase in 


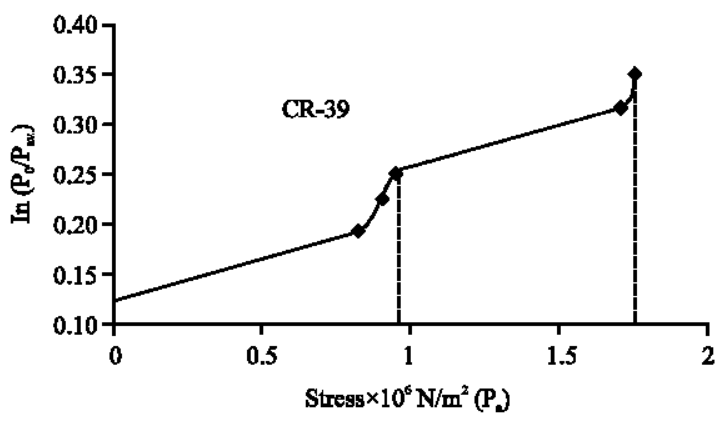

Fig. 4: The relationship between the stress effect on CR-39 with ( $\mathrm{He}-\mathrm{Ne})$ laser penetration factor $\ln \left(\mathrm{P}_{0} / \mathrm{P}_{\text {av }}\right)$

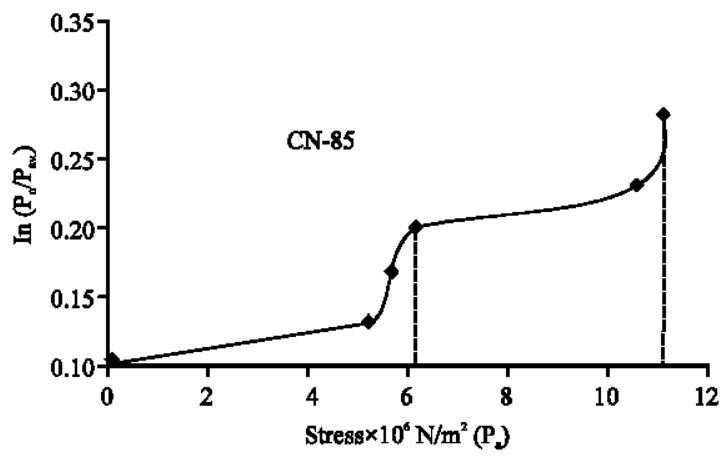

Fig. 5: The relationship between the stress effect on $\mathrm{CN}-85$ with $(\mathrm{He}-\mathrm{Ne})$ laser penetration factor $\ln \left(\mathrm{P}_{0} / \mathrm{P}_{\text {av }}\right)$

Table 1: The maximum response of $(\mathrm{He}-\mathrm{Ne})$ the penetration factor $\ln \left(\mathrm{P}_{0} / \mathrm{P}_{\mathrm{av}}\right)$ for gamma radiation and stress effect to CR-39 and CN-85 detectors

\begin{tabular}{lccrc}
\hline Detector & $\begin{array}{c}\text { Thickness } \\
(\mu \mathrm{m})\end{array}$ & \multicolumn{2}{c}{$\begin{array}{c}\text { Stress } \times 10^{6} \\
----\left(\mathrm{N} / \mathrm{m}^{2}\right)\end{array}$} & $\begin{array}{c}\text { Maximum response of } \\
\text { gamma irradiation (Gy) }\end{array}$ \\
\hline CR-39 & 1200 & 0.9 & 1.6 & 220 \\
CN-85 & 200 & 6.0 & 10.5 & 75 \\
\hline
\end{tabular}

gamma irradiation for two cases until to 75 Gy which represent of maximum response and dropping after this dose.

Mechanical stress: Figure 4 show the mechanical stress on $\mathrm{CR}-39$ detector with $(\mathrm{He}-\mathrm{Ne})$ laser penetration factor $\ln \left(\mathrm{P}_{0} / \mathrm{P}_{\text {av }}\right)$ which appear the increase in $\ln \left(\mathrm{P} / \mathrm{P}_{0}\right)_{\mathrm{av}}$ with increase of mechanical stress. The maximum stress measured at the stress value $1.6 \times 10^{6} \mathrm{~N} / \mathrm{m}^{2}$ equivalent to laser penetration factor $\ln \left(\mathrm{P}_{0} / \mathrm{P}_{\mathrm{av}}\right)$ at the value 0.32 .

Figure 5 shown the mechanical stress on $\mathrm{CN}-85$ detector with $(\mathrm{He}-\mathrm{Ne})$ laser penetration factor $\ln \left(\mathrm{P}_{0} / \mathrm{P}_{\mathrm{av}}\right)$ which appear the increase in $\ln \left(\mathrm{P}_{0} / \mathrm{P}_{\mathrm{av}}\right)$ with increase of mechanical stress. The maximum stress measured at the stress value $12 \times 10^{6} \mathrm{~N} / \mathrm{m}^{2}$ equivalent to laser penetration factor $\ln \left(\mathrm{P}_{0} / \mathrm{P}_{\text {av }}\right)$ at the value 0.3 .

This change shows in Table 1 that there is a possibility to use the laser beam to measure the effect of stress and the radiation effect of the nuclear track detectors (CR-39, CN-85) and the possibility of identifying the physical specifications of the special types for another nuclear track detectors by using these techniques.

\section{CONCLUSION}

This study showed that there is a possibility of using a penetration of $(\mathrm{He}-\mathrm{Ne})$ laser beam technique to determination the mechanical stress and gamma radiation effects on nuclear track detectors-NTDs type (CR-39, CN-85). This technique can be considered as one of the methods that reflect the specification of physical properties of another transmitted materials.

\section{REFERENCES}

Al-Jobouri, H.A., J.M. Sulaiman and A.S. Jarallah, 2012. Effect of X-ray radiation on electro-optical characteristics of CR-39 sheets by using microwave and FTIR spectroscopy techniques. J. Al Nahrain Univ. Sci., 15: 138-143.

Al-Jobouri, H.A., M.B. Ben Hamida, N.F. Tawfiq and F.H. Taha, 2015. Calibration of UV-radiation dose with irradiation time for CR-39 track detector by using UV-visible Spectrophotometer. Am. J. Mod. Energy, 1: $25-29$.

Al-Jobouri, H.A., W.T. Faaz and L.A. Najam, 2018. Effect of ultraviolet radiation on CN-85 and CR-39 detectors by UV-visible spectroscopy and (He-Ne) laser penetration techniques. Asian J. Chem., 30: 2075-2078.

Al-Saad, A.A. and S.J. Abbas, 2001. He-Ne laser transmission through etched CR-39 and CN-85 detector containing alpha- and neutron-induced tracks. Radiat. Meas., 34: 91-93.

Ali, H.K., 2006. Toughening polymer surfaces. Ph.D Thesis, University of Wollongong, Wollongong, Australia.

Chun, T.C., 2007. Investigations of the effects of UV irradiation on the etching behavior of CR-39 solid state nuclear track detector. Master Theses, Department of Physics and Materials Science, City University of Hong Kong, Hong Kong.

Kumar, V, R.G. Sonkawade, F. Singhb, A.S. Dhaliwala and R. Mehrac, 1982. Effect of ionizing radiation on CR-39 polymer. Nucl. Instr. Meth. Phys. Res., 203: 443-449.

Kumar, V., R.G. Sonkawade and A.S. Dhaliwal, 2010. Optimization of CR-39 as neutron dosimeter. Indian J. Pure Appl. Phys., 48: 466-469.

Kumar, V., R.G. Sonkawade, A.S. Dhaliwal and R. Mehra, 2009. Study of neutron induced modification on optical band gap of CR-39 polymeric detector. Asian J. Chem., 21: 279-283. 
Malek, M.A. and C.S. Chong, 2002. CO2 diffusion from X-ray and X-ray irradiated CR-39 plastic. Radiat. Meas., 35: 203-206.

Mandal, S. and N. Nagahanumaiah, 2014. Assessment of thermally induced shear stress and its effect on pattern waviness in $\mathrm{CO} 2$ laser ablation of birefringent polymers. Proc. Inst. Mech. Eng. Part E J. Process, 228: 97-103.

Mohammad, K.I. and M.I. Azawe, 2013. The development of a novel technique to evaluate the CR-39 track response to alpha particles. Turk. J. Phys., 37: 182-189.

Neamah, M.M., 2017. Studying the effects of He-Ne laser beam and gamma radiation on CR-39 detectors irradiated by a-particles using some spectroscopy techniques. Master Thesis, Nahrain University, Baghdad, Iraq.

Prasher, S., M. Narwal, S. Rana and M. Kumar, 2009. A comparative study on the influence of IR radiations to some polymers. Asian J. Chem., 21: 216-219.

Rafique, M.S., S. Bashir, A. Ajami and W. Husinsky, 2010. Nonlinear absorption properties correlated with the surface and structural changes of ultra short pulse laser irradiated CR-39. Appl. Phys. A, 100: 1183-1189.
Raouf, K.M.A., 2013. Study of CR-39 SSNDs irradiated with different types of radiation by FTIR spectroscopy and a-range determination. Am. J. Environ. Prot., 2: 53-57.

Sinenian, N., M.J. Rosenberg, M. Manuel, S.C. McDuffee and D.T. Casey et al., 2011. The response of CR-39 nuclear track detector to $1-9 \mathrm{MeV}$ protons. Rev. Sci. Instrum., Vol. 82, 10.1063/1.3653549

Sinha, D., S. Ghosh, K.K. Dwivedi and D. Fink, 1998. Structural modifications and track registration response of some gamma irradiated polycarbonate detectors. Radiat. Effects Defects Solids, 145: 45-56.

Tavera, L., M. Balcazar, H. Matamoros and H. Carrasco, 2005. CR-39 andLexan calibrated as low-LET radiation dosimeter, for three Mexican irradiation facilities. Radiat. Measure., 40: 259-263.

Wong, C.F. and P. Hoberg, 1982. A comparison of the effects of ultraviolet radiation on CR-39 and lexan plastics irradiated by alpha particles. Nucl. Instrum. Methods Phys. Res., 203: 443-449.

Zaki, M.F., T.M. Hegazy and D.H. Taha, 2013. Investigation of the effect of $\mathrm{He}-\mathrm{Ne}$ laser on the optical properties through etched CN-85 and CR-39 containing alpha tracks. Arab J. Nucl. Sci. Appl., 46: 201-210. 